\title{
Triple-Kagomé-layer slabs of mixed-valence rare-earth ions exhibiting quantum spin liquid behaviors: Synthesis and characterization of $\mathrm{Eu}_{9} \mathrm{MgS}_{2} \mathrm{~B}_{20} \mathrm{O}_{41}$
}

Yang Chi ${ }^{\dagger}, \S$, Jing $\mathrm{Xu}^{\ddagger}{ }^{\ddagger}$, Huai-Guo Xue ${ }^{\dagger}$, Yueping Zhang ${ }^{\ddagger}$, Xiaolong Chen ${ }^{\#}$, Myung-Hwan Whangbo ${ }^{\ddagger, l}, \Delta$, Sheng-Ping Guo ${ }^{\dagger}, *$, Shuiquan Deng.,*

${ }^{\dagger}$ School of Chemistry and Chemical Engineering, Yangzhou University, Yangzhou, Jiangsu 225002, P. R. China

\State Key Laboratory of Structural Chemistry, Fujian Institute of Research on the Structure of Matter, Chinese Academy of Sciences, Fuzhou, Fujian, 350002, P. R. China

${ }^{\#}$ Research \& Development Center for Functional Crystals, Beijing National Laboratory for Condensed Matter Physics, Institute of Physics, Chinese Academy of Sciences, Post Office Box 603, Beijing, 100190, P. R. China

"Department of Chemistry, North Carolina State University, Raleigh, NC 27695 - 8204, USA

${ }^{\Delta}$ State Key Laboratory of Crystal Materials, Shandong University, Jinan, 250100, P. R. China 


\section{[S1] Experimental details}

Synthesis: All chemicals were purchased and used without further purification. To a $500 \mathrm{mg}$ mixture of $\mathrm{Eu}_{2} \mathrm{O}_{3}(99.9 \%), \mathrm{Mg}(99.9 \%), \mathrm{B}(99.9 \%), \mathrm{S}(99.999 \%)$ and $\mathrm{B}_{2} \mathrm{O}_{3}$ (99.9\%) in the molar ratio of $9 \mathrm{Eu}_{2} \mathrm{O}_{3}: 2 \mathrm{Mg}: 4 \mathrm{~B}: 4 \mathrm{~S}: 18 \mathrm{~B}_{2} \mathrm{O}_{3}, 400 \mathrm{mg} \mathrm{KI}(99 \%)$ was added as flux. The starting materials were ground into fine powder in an agate mortar, pressed into a pellet, and loaded into quartz tubes. The tubes were evacuated to $1 \times 10^{-4}$ torr and flame-sealed. The sample was placed into a muffle furnace, heated from room temperature to $300{ }^{\circ} \mathrm{C}$ in $5 \mathrm{~h}$, kept at $300{ }^{\circ} \mathrm{C}$ for $5 \mathrm{~h}$, then heated to $650{ }^{\circ} \mathrm{C}$ in $5 \mathrm{~h}$, kept at $650{ }^{\circ} \mathrm{C}$ for $5 \mathrm{~h}$, then heated to $950{ }^{\circ} \mathrm{C}$ in $5 \mathrm{~h}$, kept at $950{ }^{\circ} \mathrm{C}$ for 7 days, and finally cooled down to $300{ }^{\circ} \mathrm{C}$ in 5 days. ${ }^{1}$ Using this method, crystals of Eu9Mg $\mathrm{MgS}_{2} \mathrm{~B}_{20} \mathrm{O}_{41}$ could be obtained with a moderate yield.

Single crystal data: Single crystal X-ray diffraction experiments were performed on a Bruker D8 QUEST X-ray diffractometer equipped with a graphite-monochromated Mo K $\alpha$ $(\lambda=0.71073 \AA)$ radiation at $296 \mathrm{~K}$. Within Olex $2,{ }^{2}$ the structures were solved by intrinsic phasing methods with ShelXT (Sheldrick, 2015) ${ }^{3}$ and refined by full-matrix least-squares techniques on $\mathrm{F}^{2}$ with anisotropic thermal parameters for all atoms with ShelXL (Sheldrick, 2015). ${ }^{3}$ The final refinement included anisotropic displacement parameters for all atoms and a secondary extinction correction. The crystallographic data, atomic coordinates and equivalent isotropic displacement parameters, and bond lengths are listed in Tables S1, S2 and S3, respectively. Further details can be found through: CCDC-1884657 for $\mathrm{Eu}_{9} \mathrm{MgS}_{2} \mathrm{~B}_{20} \mathrm{O}_{41}$.

EDS analysis: Semi-quantitative microscopic element analyses on single crystals were performed on a field-emission scanning electron microscope (SEM, Hitachi S-4800II) equipped with an energy dispersive X-ray spectroscope (EDS, Bruker, Quantax). They confirmed the presence of $\mathrm{Eu}, \mathrm{Mg}, \mathrm{S}$ and $\mathrm{O}$ with the molar ratio around $9: 1: 2: 41$, and no other elements were detected (B could not be detected since it is too light). The final compositions were established from the X-ray structure determination. 
XRD characterization: Crystals of $\mathrm{Eu}_{9} \mathrm{MgS}_{2} \mathrm{~B}_{20} \mathrm{O}_{41}$ have unique colors and shapes different from the other products in the reactions, which made one pick out their crystals under the microscopy easily. The powder X-ray diffraction (XRD) patterns were collected with a diffractometer (Bruker D8 Advance) at $40 \mathrm{kV}$ and $100 \mathrm{~mA}$ for $\mathrm{Cu}-K \alpha$ radiation ( $\lambda$ $=1.5406 \AA$ ) with a scan speed of $5 \%$ min at room temperature. The simulated patterns were produced using the Mercury program and single-crystal reflection data. The result indicates that the picked-out sample of $\mathrm{Eu}_{9} \mathrm{MgS}_{2} \mathrm{~B}_{20} \mathrm{O}_{41}$ is pure in the sense of the XRD detection limit ( 0.5\%) (Figure S1).

XPS analysis: X-ray photoelectron spectroscopy (Thermofisher Scientific, ESCALAB250Xi) measurements were carried out to determine the oxidation states of Eu atoms in $\mathrm{Eu}_{9} \mathrm{MgS}_{2} \mathrm{~B}_{20} \mathrm{O}_{41}$ (Figure $\mathrm{S} 2$ ).

UV-Vis absorption spectra: UV-Vis absorption spectra were measured by using a Lambda 950 UV-Vis-NIR light spectrophotometer with the wavelength range of 175-3300 $\mathrm{nm}$, with $\mathrm{BaSO}_{4}$ as the reference.

Magnetic measurements. Magnetic susceptibility measurements were performed by using a Magnetic Property Measurement System (MPMS). A collection of the picked-out small single crystals of $\mathrm{Eu}_{9} \mathrm{MgS}_{2} \mathrm{~B}_{20} \mathrm{O}_{41}(12.19 \mathrm{mg})$ was used for measurements, using a gel capsule as the sample holder, between 300 to $2 \mathrm{~K}$ with probe magnetic field at $0.2,0.1$, 0.05 , and $0.01 \mathrm{~T}$, respectively. The zero-field-cooled magnetic susceptibility was measured at $0.01 \mathrm{~T}$. The field-cooled magnetic susceptibilities were measured at $0.2,0.1$, and $0.01 \mathrm{~T}$, respectively.

Thermal property measurement: The specific heat capacity was measured at zero field from 300 to $2 \mathrm{~K}$ by means of a relaxation method linearly with a pellet ( $3 \mathrm{mg}$ ) by using a commercial Quantum Design Physical Property Measurement System (PPMS). 
Table S1. Crystallographic data and structure refinement parameters of $\mathrm{Eu}_{9} \mathrm{MgS}_{2} \mathrm{~B}_{20} \mathrm{O}_{41}$.

\begin{tabular}{|c|c|}
\hline chemical formula & $\mathrm{Eu}_{9} \mathrm{MgS}_{2} \mathrm{~B}_{20} \mathrm{O}_{41}$ \\
\hline Fw & 2328.27 \\
\hline$T(\mathrm{~K})$ & $296(2)$ \\
\hline crystal system & hexagonal \\
\hline space group & $P 6_{3} / m$ \\
\hline$Z$ & 2 \\
\hline$a(\AA)$ & $8.2708(12)$ \\
\hline$c(\AA)$ & $24.919(4)$ \\
\hline$V\left(\AA^{3}\right)$ & $1476.3(4)$ \\
\hline$D_{\text {calcd }}\left(\mathrm{g} \mathrm{cm}^{-3}\right)$ & 5.238 \\
\hline$\mu\left(\mathrm{mm}^{-1}\right)$ & 19.142 \\
\hline$F(000)$ & 2078 \\
\hline$\theta$ range $\left(^{\circ}\right)$ & 2.96 to 25.49 \\
\hline measd. reflns & 7861 \\
\hline indep. reflns/ $\mathrm{R}_{\text {int }}$ & $938 / 0.0277$ \\
\hline $\begin{array}{l}\mathrm{R} 1 / \mathrm{wR} 2 \quad(I \quad> \\
2 \sigma(I))^{\mathrm{a}}\end{array}$ & $0.0244 / 0.0497$ \\
\hline $\mathrm{R} 1 / \mathrm{wR} 2$ (all data) $^{\mathrm{a}}$ & $0.0248 / 0.0498$ \\
\hline GOF on $F^{2}$ & 1.079 \\
\hline$\Delta \rho_{\max } / \Delta \rho_{\min ,} \mathrm{e} / \AA^{3}$ & $1.148 /-0.991$ \\
\hline
\end{tabular}

${ }^{\mathrm{a}} \mathrm{R} 1=\| F_{\mathrm{o}}|-| F_{\mathrm{c}}|| /\left|F_{\mathrm{o}}\right| ; \mathrm{wR} 2=\left[w\left(F_{\mathrm{o}}{ }^{2}-F_{\mathrm{c}}{ }^{2}\right)^{2}\right] /\left[w\left(F_{\mathrm{o}}{ }^{2}\right)^{2}\right]^{1 / 2}$. 
Table S2. Atomic coordinates $\left(\times 10^{4}\right)$ and equivalent isotropic displacement parameters $\left(U_{\mathrm{eq}}{ }^{a}, \AA^{2} \times 10^{3}\right)$ for $\mathrm{Eu}_{9} \mathrm{MgS}_{2} \mathrm{~B}_{20} \mathrm{O}_{41}$.

\begin{tabular}{llllll}
\hline atom & Wyck. & \multicolumn{3}{l}{$\boldsymbol{y}$} & $\boldsymbol{U}_{\mathbf{e q}} \AA^{\mathbf{2}}$ \\
& site & & & & \\
$\mathrm{Eu}(1)$ & $12 i$ & $3352(1)$ & $11081(1)$ & $-1038(1)$ & $3(1)$ \\
$\mathrm{Eu}(2)$ & $6 h$ & $2256(1)$ & $9102(1)$ & -2500 & $5(1)$ \\
$\mathrm{Mg}(1)$ & $2 b$ & 0 & 10000 & 0 & $2(1)$ \\
$\mathrm{B}(1)$ & $12 i$ & $5942(11)$ & $8615(11)$ & $-377(3)$ & $2(2)$ \\
$\mathrm{B}(2)$ & $12 i$ & $3720(11)$ & $15167(11)$ & $-1318(3)$ & $2(2)$ \\
$\mathrm{B}(3)$ & $12 i$ & $6338(11)$ & $11357(11)$ & $-1999(3)$ & $2(2)$ \\
$\mathrm{B}(4)$ & $4 f$ & 6667 & 13333 & $-313(6)$ & $7(3)$ \\
$\mathrm{S}(1)$ & $4 e$ & 0 & 10000 & $-1711(1)$ & $5(1)$ \\
$\mathrm{O}(1)$ & $12 i$ & $4799(7)$ & $8873(7)$ & $-728(2)$ & $5(1)$ \\
$\mathrm{O}(2)$ & $12 i$ & $2961(7)$ & $8155(7)$ & $-1484(2)$ & $2(1)$ \\
$\mathrm{O}(3)$ & $12 i$ & $4825(7)$ & $11796(7)$ & $-1939(2)$ & $2(1)$ \\
$\mathrm{O}(4)$ & $4 f$ & 6667 & 13333 & $-885(4)$ & $5(2)$ \\
$\mathrm{O}(5)$ & $12 i$ & $7958(7)$ & $12659(7)$ & $-132(2)$ & $4(1)$ \\
$\mathrm{O}(6)$ & $12 i$ & $858(7)$ & $8592(7)$ & $-527(2)$ & $4(1)$ \\
$\mathrm{O}(7)$ & $12 i$ & $3968(7)$ & $13709(7)$ & $-1538(2)$ & $3(1)$ \\
$\mathrm{O}(8)$ & $6 h$ & $6089(10)$ & $10343(10)$ & -2500 & $3(1)$ \\
\hline
\end{tabular}

${ }^{a} U_{\text {eq }}$ is defined as one third of the trace of the orthogonalized $U_{i j}$ tensor. 
Table S3. Selected bond distances $(\AA)$ of $\mathrm{Eu}_{9} \mathrm{MgS}_{2} \mathrm{~B}_{20} \mathrm{O}_{41}{ }^{\text {a }}$

\begin{tabular}{llllll}
\hline Bond & Dist. & Bond & Dist. & Bond & Dist. \\
\hline $\mathrm{Eu}(1)-\mathrm{O}(1)$ & $2.748(5)$ & $\mathrm{Eu}(2)-\mathrm{O}(3)$ & $2.589(5)$ & $\mathrm{B}(2)-\mathrm{O}(2) \# 2$ & $1.484(9)$ \\
$\mathrm{Eu}(1)-\mathrm{O}(2)$ & $2.533(5)$ & $\mathrm{Eu}(2)-\mathrm{O}(8)$ & $2.801(7)$ & $\mathrm{B}(2)-\mathrm{O}(7)$ & $1.429(9)$ \\
$\mathrm{Eu}(1)-\mathrm{O}(3)$ & $2.479(5)$ & $\mathrm{Eu}(2)-\mathrm{O}(8) \# 4$ & $2.522(7)$ & $\mathrm{B}(3)-\mathrm{O}(3)$ & $1.475(9)$ \\
$\mathrm{Eu}(1)-\mathrm{O}(4)$ & $2.455(2)$ & $\mathrm{Eu}(2)-\mathrm{S}(1)$ & $3.047(2)$ & $\mathrm{B}(3)-\mathrm{O}(3) \# 3$ & $1.477(9)$ \\
$\mathrm{Eu}(1)-\mathrm{O}(5) \# 1$ & $2.468(5)$ & $\mathrm{Mg}(1)-\mathrm{O}(6)$ & $2.100(5)$ & $\mathrm{B}(3)-\mathrm{O}(7) \# 3$ & $1.451(9)$ \\
$\mathrm{Eu}(1)-\mathrm{O}(6)$ & $2.423(5)$ & $\mathrm{B}(1)-\mathrm{O}(1)$ & $1.381(1)$ & $\mathrm{B}(3)-\mathrm{O}(8)$ & $1.460(8)$ \\
$\mathrm{Eu}(1)-\mathrm{O}(6) \# 2$ & $2.597(5)$ & $\mathrm{B}(1)-\mathrm{O}(5) \# 11$ & $1.377(1)$ & $\mathrm{B}(4)-\mathrm{O}(4)$ & $1.426(2)$ \\
$\mathrm{Eu}(1)-\mathrm{O}(7)$ & $2.330(5)$ & $\mathrm{B}(1)-\mathrm{O}(6) \# 10$ & $1.371(1)$ & $\mathrm{B}(4)-\mathrm{O}(5)$ & $1.500(7)$ \\
$\mathrm{Eu}(1)-\mathrm{S}(1)$ & $2.969(2)$ & $\mathrm{B}(2)-\mathrm{O}(1) \# 1$ & $1.498(9)$ & & \\
$\mathrm{Eu}(2)-\mathrm{O}(2)$ & $2.796(5)$ & $\mathrm{B}(2)-\mathrm{O}(2) \# 1$ & $1.472(9)$ & & \\
\hline
\end{tabular}

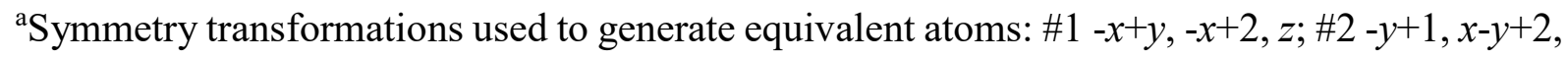
$z$; \#3 -y+2, $x-y+2, z ; \# 4-y+1, x-y+1, z ; \# 5 x, y,-z-1 / 2 ; \# 6-x+y-1,-x+1, z ; \# 7 x-y+1, x+1,-z$; \#8 $y-1,-x+y,-z ; \# 9-x,-y+2,-z ; \# 10-x+y,-x+1, z ; \# 11 x-y+1, x,-z ; \# 12 y,-x+y+1,-z$. 


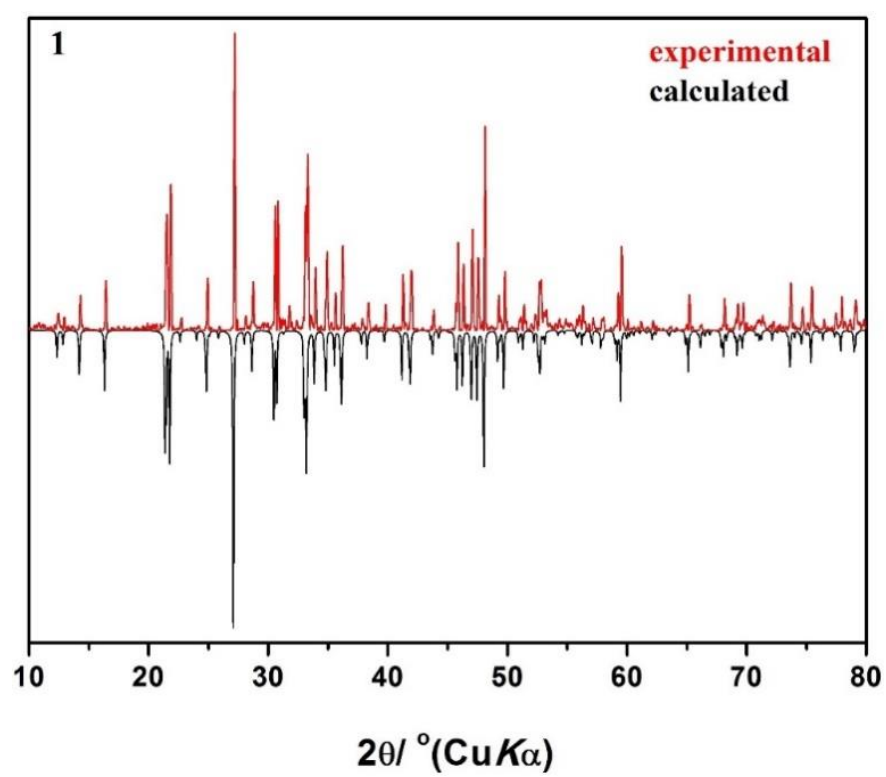

Figure S1. Powder X-ray diffraction pattern of Eug $\mathrm{MgS}_{2} \mathrm{~B}_{20} \mathrm{O}_{41}$. 


\section{[S2] Structure description}

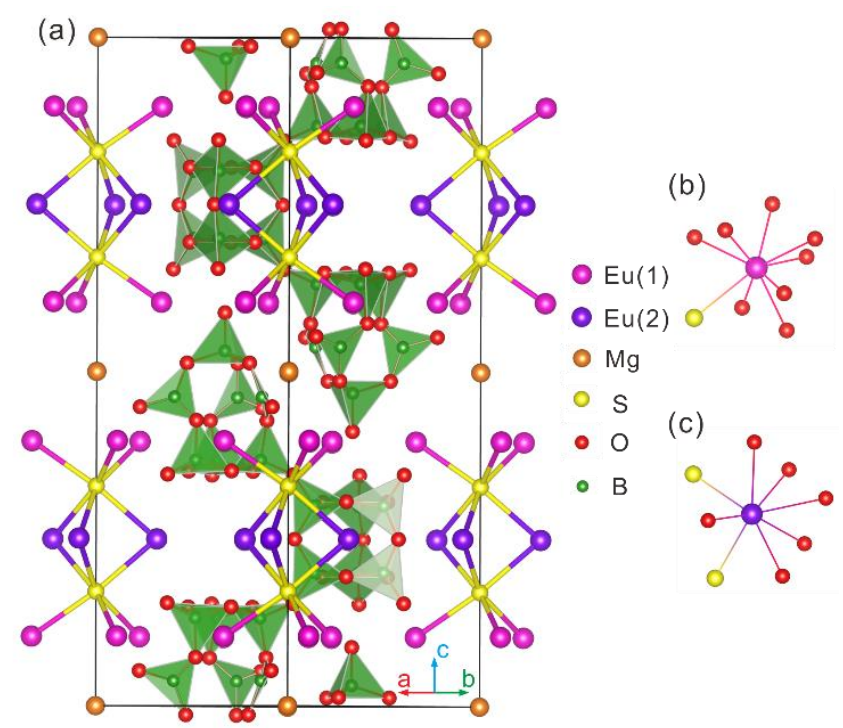

Figure S2. (a) Crystal structure of $\mathrm{Eu}_{9} \mathrm{MgS}_{2} \mathrm{~B}_{20} \mathrm{O}_{41}$. (b) Coordination environment of $\mathrm{Eu}(1)$ with a site symmetry $C_{1}$. (c) Coordination environment of $\mathrm{Eu}(2)$ with a site symmetry of $\mathrm{C}_{\mathrm{s}}$.

(a)

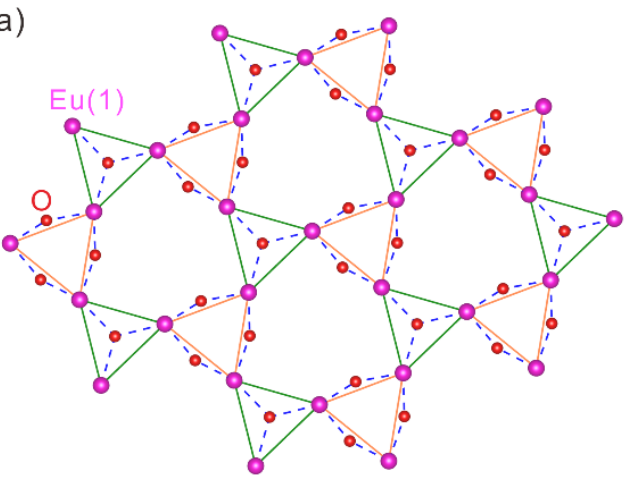

(b)

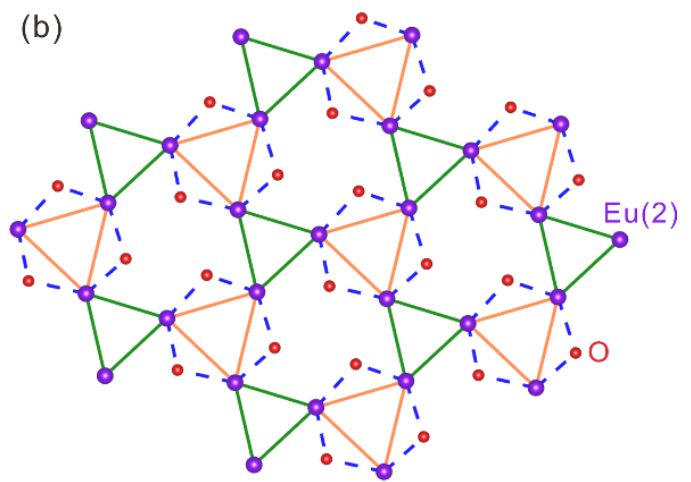

Figure S3. (a) Top projection view of the distorted Kagomé layer of $\mathrm{Eu}(1)$, i.e. $\mathrm{Eu}^{3+}$ ions. (b) Top projection view of the distorted Kagomé layer of $\mathrm{Eu}(2)$, i.e. $\mathrm{Eu}^{2+}$ ions. The bridging and capping oxygen atoms to the rare-earth atoms are also shown. 


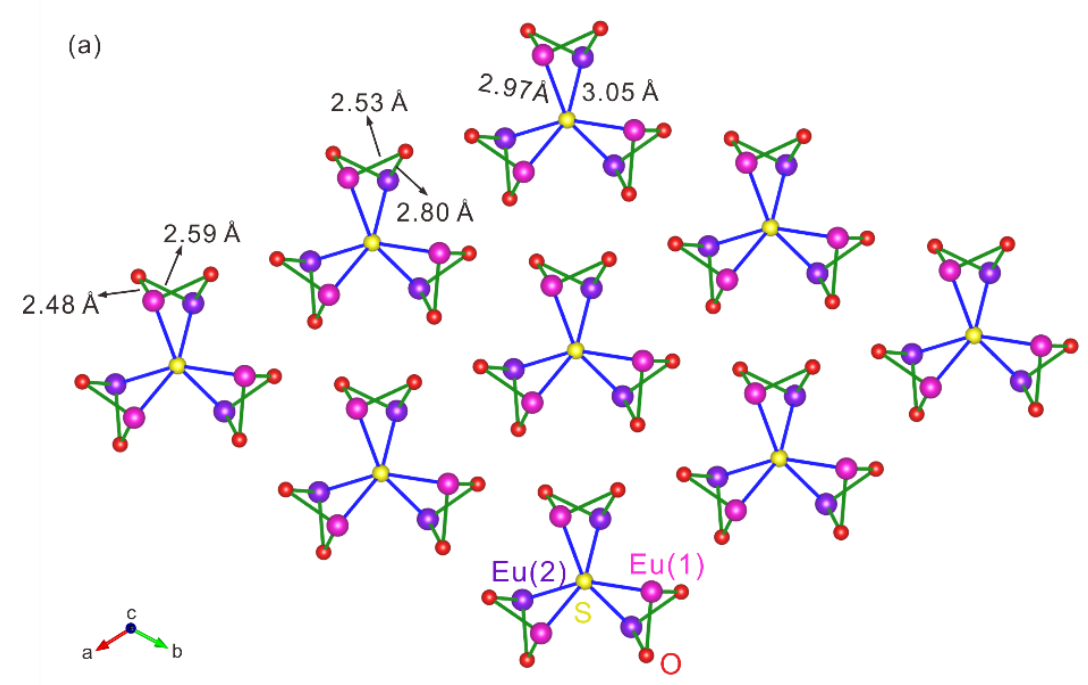

(b)

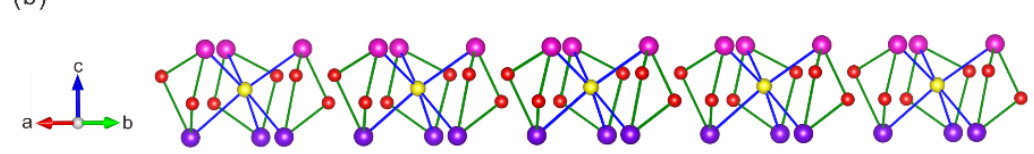

Figure S4. (a) Top projection view of two adjacent Kagomé layers of the $\mathrm{Eu}(1) / \mathrm{Eu}(2)$ atoms. (b) Side projection view of two adjacent Kagomé layers of the $\mathrm{Eu}(1) / \mathrm{Eu}(2)$ atoms. The $\mathrm{O}$ and $\mathrm{S}$ atoms bridging the two Kagomé layers are also shown.

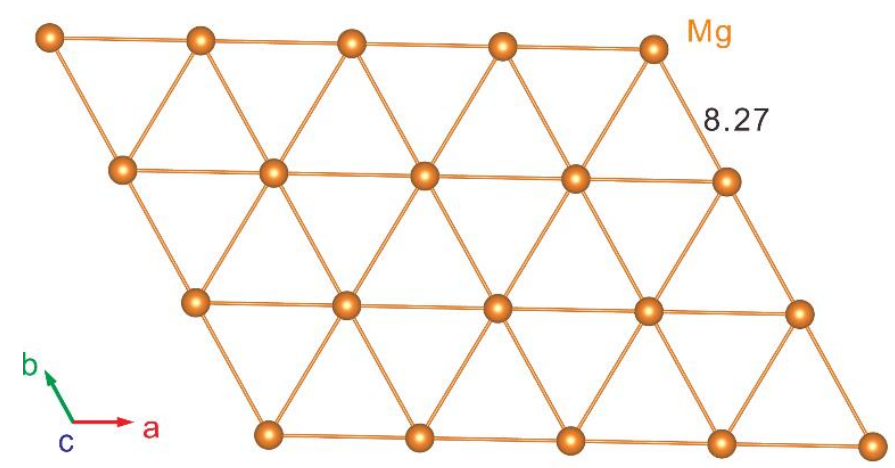

Figure S5. The triangular lattice of the $\mathrm{Mg}^{2+}$ ions lying between the triple-Kagomé-layer slabs. 

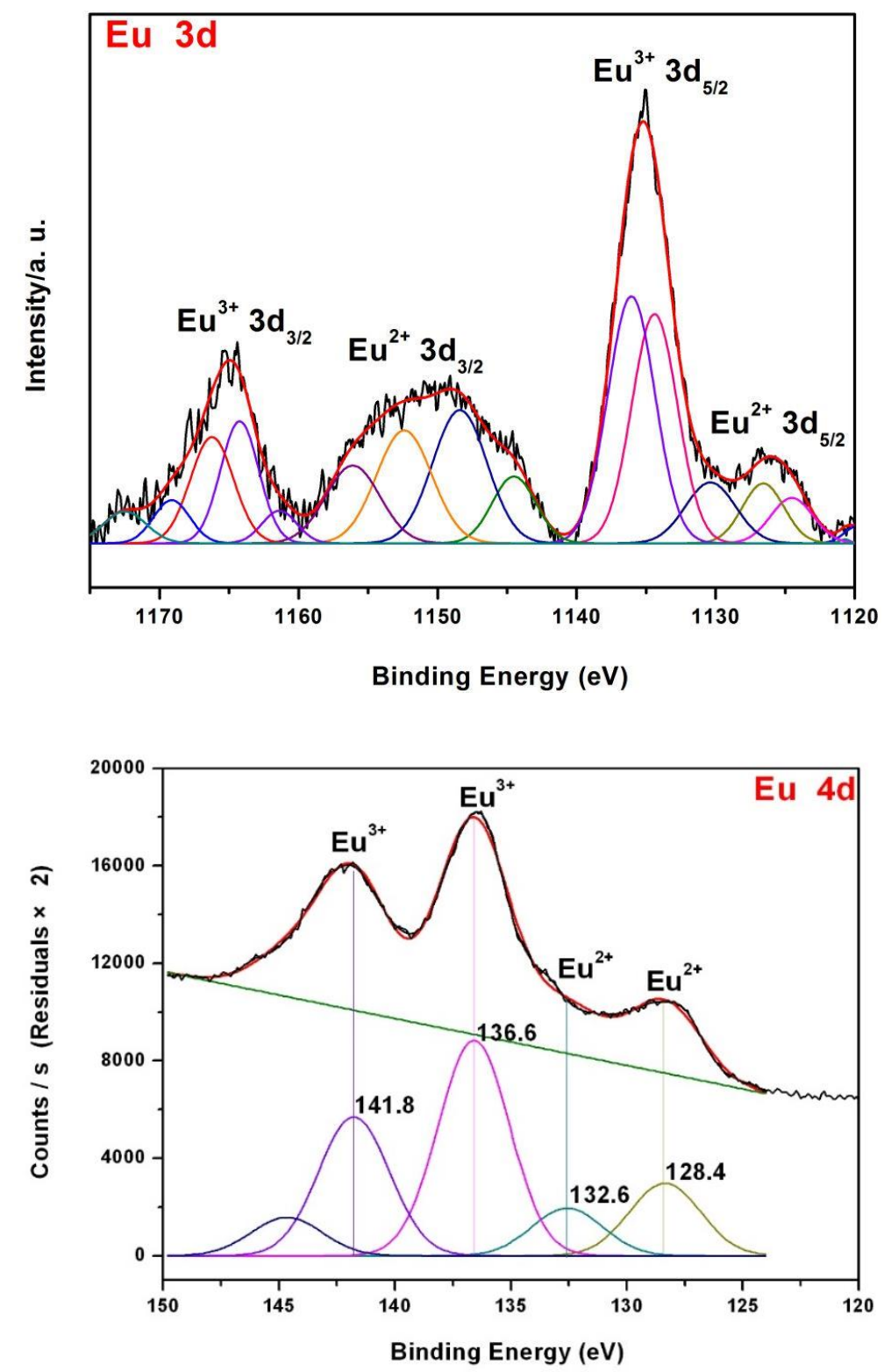

Figure S6. XPS $3 d$ and $4 d$ spectra of $\mathrm{Eu}_{9} \mathrm{MgS}_{2} \mathrm{~B}_{20} \mathrm{O}_{41}$ and their analyses to indicate the oxidation states of Eu ions.

Table S4. Calculated Bader charges of each type of atoms in $\mathrm{Eu}_{9} \mathrm{MgS}_{2} \mathrm{~B}_{20} \mathrm{O}_{41}$.

\begin{tabular}{cccccccc}
\hline \multirow{2}{*}{ Atom } & \multicolumn{2}{c}{$\mathrm{Eu}$} & $\mathrm{Mg}$ & $\mathrm{B}$ & $\mathrm{S}$ & $\mathrm{O}$ \\
\cline { 2 - 5 } & $\mathrm{Eu}(1)$ & $\mathrm{Eu}(2)$ & & & & \\
\hline Bader Charge & 2.03 & 1.81 & 1.73 & 2.33 & -1.24 & -1.54 \\
\hline
\end{tabular}



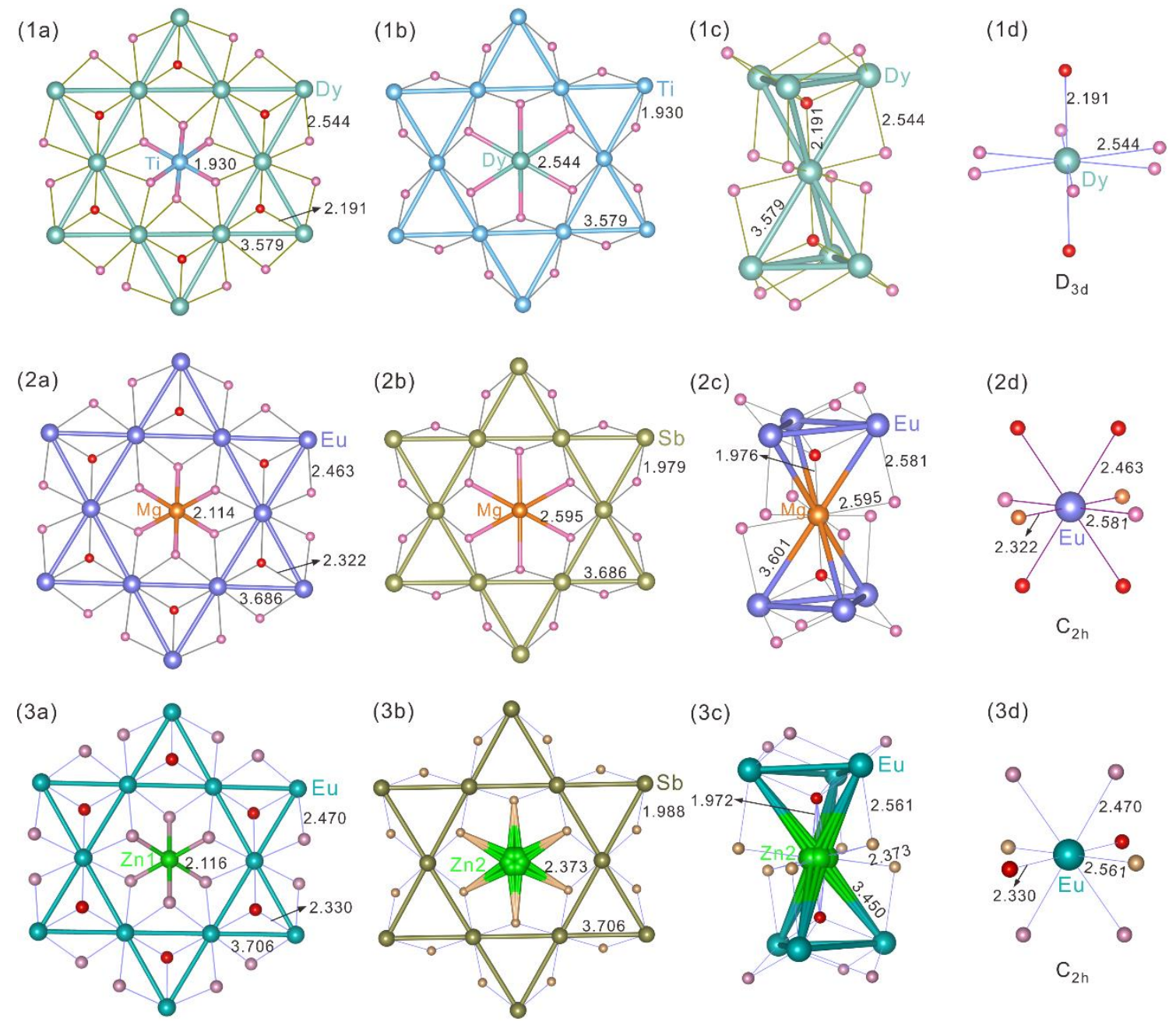

$(3 d)$

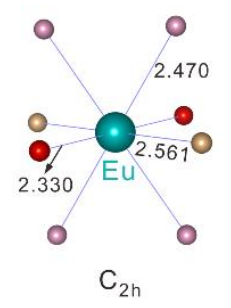

Figure S7. Structures of $\mathrm{RE}_{2} \mathrm{M}_{2} \mathrm{O}_{7}$ family (1a-d for $\mathrm{RE}=\mathrm{Dy}, \mathrm{M}=\mathrm{Ti}$ ), and those of $\mathrm{RE}_{3} \mathrm{Sb}_{3} \mathrm{M}_{2} \mathrm{O}_{14}$ family (2a-d, 3a-d for $\mathrm{RE}=\mathrm{Eu} ; \mathrm{M}=\mathrm{Mg}$ and $\mathrm{Zn}) .{ }^{4}$ Throughout this work, we use the notation $\mathrm{X}^{\mathrm{n}+}-\mathrm{Y}^{\mathrm{m}+}$ to denote a Kagomé lattice formed by $\mathrm{X}^{\mathrm{n}+}$ ions, with the $\mathrm{Y}^{\mathrm{m}+}$ ions occupying the hexagon centers of the Kagomé lattice. In this notation, (1a), (2a), and (3a) show the $\mathrm{Dy}^{3+}{ }_{-} \mathrm{Ti}^{4+}$, $\mathrm{Eu}^{3+}{ }_{-} \mathrm{Mg}^{2+}$, and the $\mathrm{Eu}^{3+} \mathrm{Zn}^{2+}$ Kagomé lattices, respectively. (1b), (2b), and (3b) show the $\mathrm{Ti}^{4+} \mathrm{Dy}^{3+}, \mathrm{Sb}^{5+}{ }_{-} \mathrm{Mg}^{2+}$, and $\mathrm{Sb}^{5+} \mathrm{Zn}^{2+}$ Kagomé lattices, respectively. (1c), (2c), and (3c) are the perspective views for the local environments of the ions located at the hexagon centers in (1b), (2b), and (3b), respectively. (1d), (2d), and (3d) show the coordination environments, with site symmetry indicated, of the rare-earth ions in the Kagomé lattices shown in (1a), (2a), and (3a), respectively. 

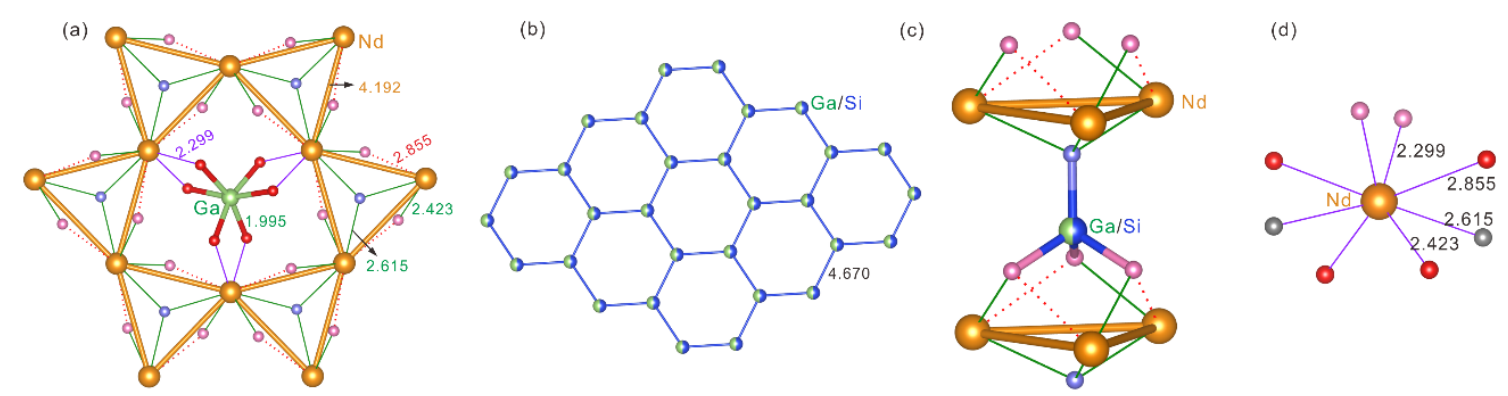

Figure S8. (a) $\mathrm{RE}^{3+} \mathrm{Ga}^{3+}$ Kagomé lattice of $\mathrm{RE}_{3} \mathrm{Ga}_{5} \mathrm{SiO}_{14}$ represented with $\mathrm{RE}=\mathrm{Nd}$ (b) The projection of the slightly puckered $\mathrm{Ga} / \mathrm{Si}$ hexagonal network located between two $\mathrm{Nd}^{3+} \mathrm{Ga}^{3+}$ Kagomé layers. (c) The local environment of $\mathrm{Ga} / \mathrm{Si}$ ions showing how two $\mathrm{RE}^{3+} \mathrm{Ga}^{3+}$ Kagomé layers are connected. (d) The coordination environment of the $\mathrm{Nd}^{3+}$ ion with a site symmetry $\mathrm{C}_{2}{ }^{5}$

From Figure S7 and Figure S8, it is obvious that the rare-earth Kagomé layers denoted as $\mathrm{Dy}^{3+}{ }_{-} \mathrm{Ti}^{4+}, \mathrm{Eu}^{3+}{ }_{-} \mathrm{Mg}^{2+}, \mathrm{Eu}^{3+} \mathrm{Zn}^{2+}$ and $\mathrm{Nd}^{3+} \mathrm{Ga}^{3+}$ in the three different families are actually very similar, given that the ions $\mathrm{Ti}^{4+}, \mathrm{Mg}^{2+}, \mathrm{Zn}^{2+}$ and $\mathrm{Ga}^{3+}$, occupying the hexagon centers are all non-magnetic. Such nonmagnetic ions are often neglected in the literature ${ }^{6}$ when describing the Kagomé structures, though Sanders et $a l .{ }^{4 c}$ have clearly indicated the positions of $\mathrm{Zn}^{2+}$ ions in their structures. The structural differences among them manifest in the columns (b) and (c) of Figure S7 and Figure S8. As can be seen from Figure S7 (1a-c), the interactions between the $\mathrm{Dy}^{3+}$ ions within and outside the Kagomé layer are comparable, which renders the $\mathrm{RE}_{2} \mathrm{M}_{2} \mathrm{O}_{7}$ family a three dimensional pyrochlore type interaction instead of a Kagomé one. In the $\mathrm{RE}_{3} \mathrm{Sb}_{3} \mathrm{M}_{2} \mathrm{O}_{14}$ and $\mathrm{RE}_{3} \mathrm{Ga}_{5} \mathrm{SiO}_{14}$ families, the Kagomé layers are separated by a non-magnetic Kagomé layer (Figure S7 (2b), (3b), Figure S8 (b)), which makes them a single-Kagomé layer system.

In contrast, the Kagomé layers (Figure 1 (a) (b); $\mathbf{S 3}$ (a), (b)) in EMSBO of this work contain no hexagon-centered ions. In addition, the shortest interlayer $\mathrm{Eu}^{3+}-\mathrm{Eu}^{2+}$ distance within the triple- Kagomé-layer slab is $\sim 3.9 \AA$, which is even smaller than the intra-layer $\mathrm{Eu}^{3+}-\mathrm{Eu}^{3+}(\sim 4.2$ $\AA$ ) or $\mathrm{Eu}^{2+}-\mathrm{Eu}^{2+}(\sim 4.0 \AA)$ distances (Figure 1a, b), implying that the Kagomé layers within the 
triple-Kagomé-layer slab may have significant inter-layer interactions (see Figure 1 (c), Figure S4 and Table S5), while such interactions between the slabs are absent due to the large space occupied by the nonmagnetic trigonal layers of $\mathrm{Mg}^{2+}$ ions (see Figure 1 (d), Figure S5) and other $\mathrm{BO}_{\mathrm{n}}$ groups (Figure S2). The inter-slab $\mathrm{Eu}^{3+}-\mathrm{Eu}^{3+}$ distance is $\sim 5.7 \AA$, which is comparable to the inter-layer $\mathrm{RE}^{3+}-\mathrm{RE}^{3+}$ distances $\sim 6.1 \AA$ and $\sim 5.1 \AA$ in the $\mathrm{RE}_{3} \mathrm{M}_{2} \mathrm{Sb}_{3} \mathrm{O}_{14}$ and $\mathrm{RE}_{3} \mathrm{Ga}_{5} \mathrm{SiO}_{14}$, respectively. These facts indicate that the magnetic interactions in EMSBO are characteristic of a triple-Kagomé-layer and are free of embedded hexagon centered ions. These features differ from the RE-pyrochlore and single RE-Kagomé layers present in $\mathrm{RE}_{2} \mathrm{M}_{2} \mathrm{O}_{7}, \mathrm{RE}_{3} \mathrm{Sb}_{3} \mathrm{M}_{2} \mathrm{O}_{14}$ and $\mathrm{RE}_{3} \mathrm{Ga}_{5} \mathrm{SiO}_{14}$ families.

Another important issue is the disorder effect. Here we focus on the "site disorder", by which we mean (I) a statistical occupation of a Wyckoff site by different atoms and (II) a partial occupation of a Wyckoff site. It has been discussed that site disorder can change the crystal field of a rare-earth ion, change its ground state, modify the spin-spin correlation ${ }^{7}$ and, in particular, mimic the spin-liquid behavior ${ }^{8}$. In practice, it is difficult to include the site disorders into the magnetic models explicitly, thus their effects may be attributed to some other factors. In the $\mathrm{RE}_{3} \mathrm{M}_{2} \mathrm{Sb}_{3} \mathrm{O}_{14}$ family, site disorders have been widely observed for large $\mathrm{M}^{2+}$ ions such as $\mathrm{Zn}^{2+4 c, 6 b, 7}$ and $\mathrm{Ca}^{2+9}$ with the latter being the first member discovered in this family. For $\mathrm{M}$ $=\mathrm{Zn}^{2+}$, Sanders et al. ${ }^{4 \mathrm{c}}$ assumed a type II site disorder for the $\mathrm{Zn}^{2+}$ in the $\mathrm{Sb}^{5+} \mathrm{Zn}^{2+}$ layer, while assuming a fully ordered model for the $\mathrm{RE}^{3+} \mathrm{Zn}^{2+}$ layer with $\mathrm{RE}=\mathrm{La}, \mathrm{Pr}, \mathrm{Nd}, \mathrm{Sm}, \mathrm{Eu}$, and $\mathrm{Gd}$. In contrast, Dun et al. ${ }^{6 b}$ have assumed a type I site disorder at the RE site (Zn 1\%-5\%) of the $\mathrm{RE}^{3+} \mathrm{Zn}^{2+}$ layer with $\mathrm{RE}=\mathrm{Pr}, \mathrm{Nd}, \mathrm{Gd}, \mathrm{Tb}$, and $\mathrm{Dy}$, while for $\mathrm{RE}=\mathrm{Ho}, \mathrm{Er}, \mathrm{Yb}$ the disorder is even more serious, $(\mathrm{Zn} \sim 40 \%)$. For $\mathrm{M}=\mathrm{Mg}^{2+}$, Sanders et $a l .{ }^{4 \mathrm{~b}}$ assumed a model without any disorder. However, Dun et al. ${ }^{6 \mathrm{~b}}$ assumed also a type I site disorder for the RE site (Mg 1\%-5\%), though their earlier work ${ }^{6 a}$ did not mention about this. Paddison et al. ${ }^{10}$ have also assumed a similar site disorder model for the Dy site $(\mathrm{Mg} 6 \%)$ of the $\mathrm{Dy}^{3+} \mathrm{Mg}^{2+}$ layer and a site disorder model for the $\mathrm{Mg}$ site $\left(\mathrm{Dy} \sim 18 \%\right.$ ) of the $\mathrm{Sb}^{5+}{ }_{-} \mathrm{Mg}^{2+}$ layer. It is clear that even if the controversies on the site disorders are neglected, the site disorders in the RE- Kagomé layer and in the nonmagnetic layer will change, to some extent, the Kagomé character of the magnetic interactions. Their effects may be explained as due to the spin disorders such as the "possible 
QSL"6a, 6b, 7 , spin glass $(\mathrm{SG})^{6 \mathrm{~b}}$, or emergent charge order $(\mathrm{ECO})^{6 \mathrm{a}, 6 \mathrm{~b}, 10}$, of which ECO is an emergent magnetic charge order state formed by disordered Ising spins ${ }^{10}$.

The site disorder problem in $\mathrm{RE}_{3} \mathrm{Ga}_{5} \mathrm{SiO}_{14}$ family ${ }^{11}$ is less serious than that in the $\mathrm{RE}_{3} \mathrm{Sb}_{3} \mathrm{M}_{2} \mathrm{O}_{14}$ family with respect to the magnetic properties, since the site disorders occur in the $\mathrm{Ga} / \mathrm{Si}$ layer lying between the magnetic Kagomé layers (Figure S8). However, as can be seen from Figure S8, the site disorder at the $\mathrm{Ga} / \mathrm{Si}$ site can displace the capping $\mathrm{O}$ and the bridging $\mathrm{O}$ ligands bonded to two neighbouring $\mathrm{RE}^{3+} \mathrm{Ga}^{3+}$ layers. This can modulate the $\mathrm{RE}^{3+} \ldots \mathrm{RE}^{3+}$ distances within the $\mathrm{RE}^{3+} \mathrm{Ga}^{3+}$ layer. The effect of the site disorders in $\operatorname{Pr}_{3} \mathrm{Ga}_{5} \mathrm{SiO}_{14}$ has been studied by Zhou et al. ${ }^{12}$ under the name of "chemical pressure" with $\mathrm{Al}$, $\mathrm{Ge}$, and $\mathrm{Ti}$ as nonmagnetic substituents for the $\mathrm{Ga}$ and $\mathrm{Si}$ sites. The experiments indicated that the "possible QSL" ground state can indeed be destroyed by spin-freezing.

Another important issue is the crystal field effect which can change the ground state of a magnetic ion. It is also an important channel through which the site disorder of the ions (even if nonmagnetic), located at the hexagonal centres of the Kagomé lattice, can get involved in the magnetic interactions. For this reason, we have also given the site symmetry groups for the magnetic rare-earth ions in Figure S2, S7 and S8 for comparison. It is obvious that the $\mathrm{Eu}^{3+}$ and $\mathrm{Eu}^{2+}$ ions in the EMSBO have the lowest site symmetries $\mathrm{C}_{1}, \mathrm{C}_{\mathrm{s}}$, respectively, among all rare earth Kagomé compounds we discussed.

From the above descriptions and discussions, it is clear that the EMSBO has a very unique heterogeneous triple-Kagomé-layer slab structure among the known rare-earth Kagomé families. Most importantly, it is free of site disorder which creates a rather rugged energy landscape for the spin disorder phenomena and complicates their explanations. 


\section{[S3] Details of DFT calculations}

\section{Computational details}

All calculations were performed by using the Vienna ab initio simulation package (VASP) ${ }^{13}$ based on the density functional theory $(\mathrm{DFT})^{14}$ and the generalized gradient approximation (GGA) of Perdew-Burke-Ernzerhof $(\mathrm{PBE})^{15}$ for the exchange-correlation functional. The $\mathrm{L}(\mathrm{S}) \mathrm{DA}+\mathrm{U}^{16}$ method was used to treat the strongly correlated $4 \mathrm{f}$ electrons. The values of the parameter $\mathrm{U}$ and the exchange integral $\mathrm{J}$ for the $4 \mathrm{f}$ electrons of Eu ions are chosen from a literature ${ }^{17}$ as 6.65 and $0.68 \mathrm{eV}$, respectively, without any optimization. Our LSDA calculations indicate that without considering the strong correlation effect the upper $\mathrm{f}$ bands will occur at wrong positions, i.e. at much lower energies. In this work, the basis sets for $\mathrm{Eu}, \mathrm{S}, \mathrm{Mg}, \mathrm{B}, \mathrm{O}$ correspond to $4 f^{7} 5 s^{2} 5 p^{6} 6 s^{2}, 3 s^{2} 3 p^{4}, 2 p^{6} 3 s^{2}, 2 s^{2} 2 p^{1}$, and $2 s^{2} 2 p^{4}$, respectively. The convergence tolerance of the total energy was set at $1 \times 10^{-4} \mathrm{eV}$, and that of the maximum force in geometry optimization at $0.01 \mathrm{eV} / \AA \AA$. The Monkhorst-Pack scheme for k-points grid $4 \times 4 \times 2$ was used, and the plane wave basis set energy cutoff was set at $550 \mathrm{eV}$. The tetrahedron method with Blöchl corrections was utilized in the integrations. 


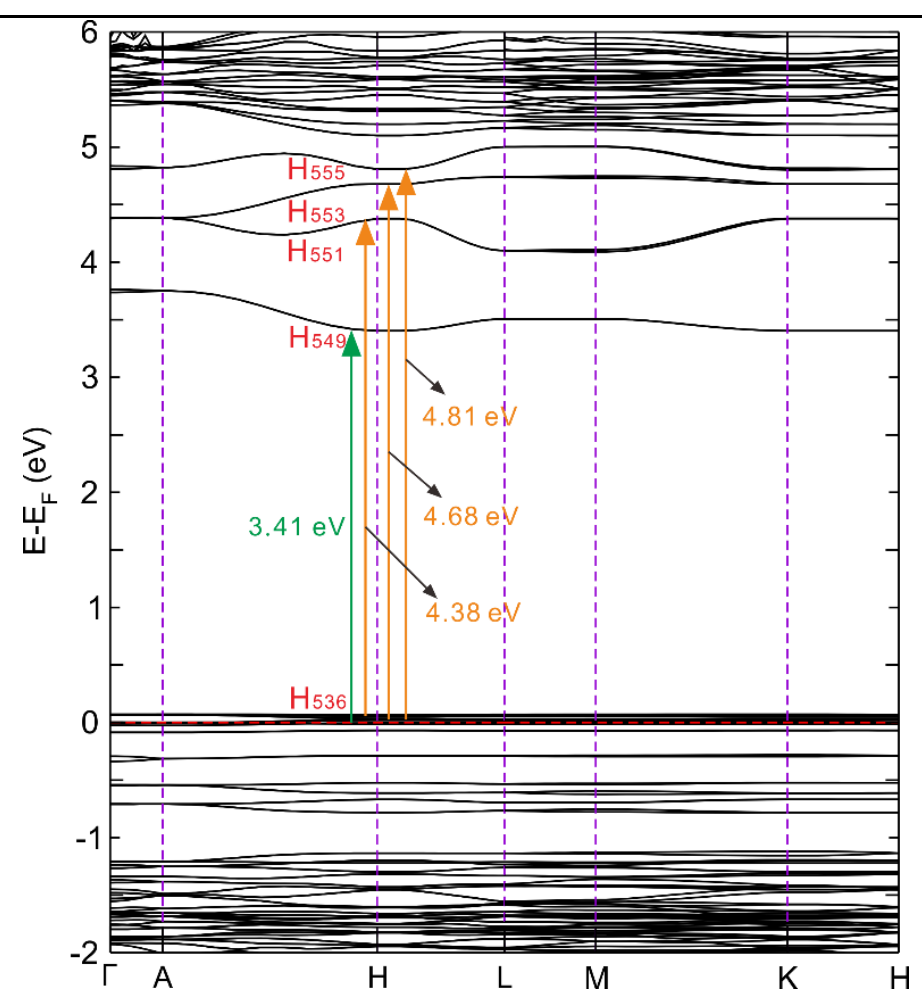

Figure S9. Band structure for the up-spin bands of $\mathrm{Eu}_{9} \mathrm{MgS}_{2} \mathrm{~B}_{20} \mathrm{O}_{41}$.

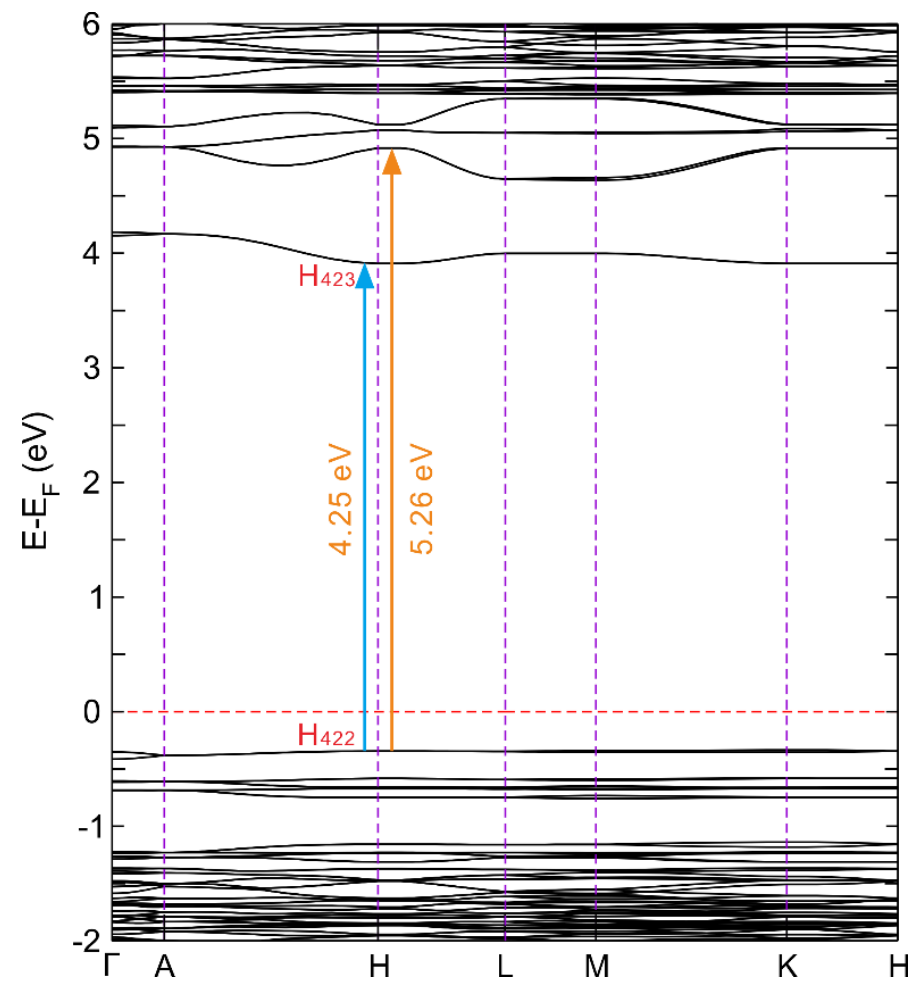

Figure S10. Band structure for the down-spin bands of $\mathrm{Eu}_{9} \mathrm{MgS}_{2} \mathrm{~B}_{20} \mathrm{O}_{41}$. 
(a)

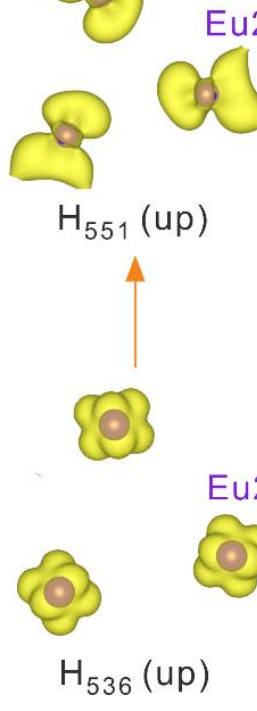

(b)

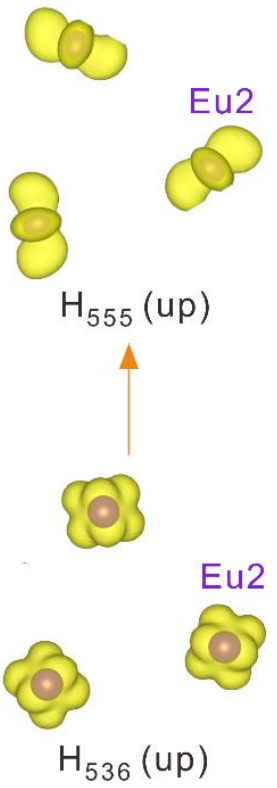

(c)
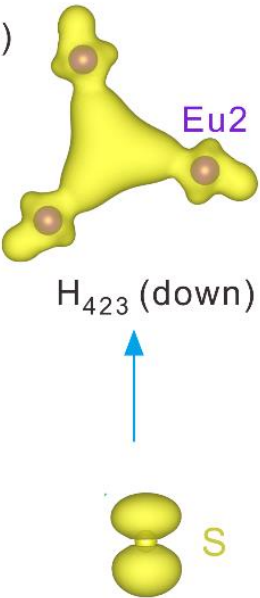

$\mathrm{H}_{422}$ (down)

Figure S11. Band orbital characters in the density representation for the $H_{536} \rightarrow H_{551}, H_{536} \rightarrow$ $H_{555}$ and $H_{422} \rightarrow H_{423}$ transitions. 


\section{[S4] Inter-valence charge transfer (IVCT)}

Estimation of the extent of IVCT. ${ }^{18}$ Consider a mixed-valence system in which the metal ions $\mathrm{M}^{2+}$ and $\mathrm{M}^{3+}$, separated by the distance of $\mathrm{R}$, are bridged by ligand atom $\mathrm{L}$. In the present case, $\mathrm{M}=\mathrm{Eu}, \mathrm{R}=3.91 \AA$ and $\mathrm{L}=\mathrm{O}$ and $\mathrm{S}$. The extent of the interaction between the two ions can be described by considering the donor orbital $\psi_{\mathrm{D}}$ on $\mathrm{M}^{2+}$ and the acceptor orbital $\psi_{\mathrm{A}}$ on $\mathrm{M}^{3+} .^{18}$ This interaction mixes $\psi_{\mathrm{D}}$ and $\psi_{\mathrm{A}}$ leading to the new states $|0\rangle$ and $|1\rangle$,

$$
\begin{aligned}
& |0\rangle=\psi_{\mathrm{D}}+\xi \psi_{\mathrm{A}} \\
& |1\rangle=\xi \psi_{\mathrm{D}}-\psi_{\mathrm{A}}
\end{aligned}
$$

where $\xi$ is the mixing coefficient. Then, the transition dipole moment for the excitation from $|0\rangle$ and $|1\rangle$ is written as

$$
\left|\overrightarrow{\mathrm{M}}_{01}\right|=\mathrm{e} \sum_{\mathrm{i}}\left|\left\langle 0\left|\overrightarrow{\mathrm{r}}_{\mathrm{i}}\right| 1\right\rangle\right|=\mathrm{e} \xi \mathrm{R}
$$

The $\xi$ value can be estimated from experiment by analyzing the oscillator strength $f$ of the IVCT absorption:

$$
f=4.319 \times 10^{-9} \int \varepsilon(\bar{v}) \mathrm{d} \bar{v}=1.085 \times 10^{-5} \bar{v} \mathrm{D}^{2}
$$

where $\varepsilon(\bar{v})$ is molar decadic extinction coefficient, $\bar{v}$ the frequency in $\mathrm{cm}^{-1}$, and $\mathrm{D}=\left|\mathrm{M}_{01}\right| / \mathrm{e}$ in $\AA$. An IVCT band is well approximated by a Gaussian shape, so that

$$
f=4.6 \times 10^{-9} \varepsilon_{\max } \Delta_{1 / 2}
$$

where $\Delta_{1 / 2}$ is the half width at half maximum of the $\varepsilon(\bar{v})$ vs. $\bar{v}$ curve in $\mathrm{cm}^{-1}$. For the IVCT band of Figure 2a, $\varepsilon_{\max }=3.6 \times 10^{3}, \Delta_{1 / 2}=2.98 \times 10^{4} \mathrm{~cm}^{-1}$, thus $f=0.49$, so that $\mathrm{D}=1.66 \AA$. Therefore, $\xi=0.42$ and $\xi^{2}=0.18$. 
Effect of IVCT on the effective magnetic moment. Assuming that the total time for one electron to hop from $\mathrm{Eu}^{2+}$ site to $\mathrm{Eu}^{3+}$ site is $T$, the time for this electron to stay with $\mathrm{Eu}^{2+}$ is $\alpha T$, where $\alpha$ is a parameter, then from $t=0$ to $\alpha T$ the magnetic moments of $\mathrm{Eu}^{2+}$ and $\mathrm{Eu}^{3+}$ will remain unchanged, here we take the experimental values 6.9 and $3.5 \mu_{B}$ for $\mathrm{Eu}^{2+}$ and $\mathrm{Eu}^{3+}$ respectively. From the time $t=\alpha T$ on, the $\mathrm{Eu}^{2+}$ ion core feels the leaving of the electron, and its magnetic moment starts to decrease, described by $\mu_{1}(t)$, with the increase of time $t$ until a minimum value $\geq 3.5 \mu_{B}$, simultaneously the magnetic moment of the $\mathrm{Eu}^{3+}$ ion starts to increase, described by $\mu_{2}(t)$, until a maximum value $\leq 6.9 \mu_{B}$. With these considerations, the average magnetic moment of the system can be calculated as follows,

$$
\begin{aligned}
\mu_{e f f}= & \frac{3 \int_{0}^{\alpha T} 6.9 d t+3 \int_{\alpha T}^{T} \mu_{1}(t) d t+6 \int_{0}^{\alpha T} 3.5 d t+6 \int_{\alpha T}^{T} \mu_{2}(t) d t}{9 T} \\
& =4.63 \alpha+\frac{3 \int_{\alpha T}^{T} \mu_{1}(t) d t+6 \int_{\alpha T}^{T} \mu_{2}(t) d t}{9 T} .
\end{aligned}
$$

If charge conservation is considered in the IVCT process, the sum of the two integration terms should be zero. As $\alpha$ is smaller than one, the time average value due to the IVCT or charge fluctuation will always lead to a reduction of the magnetic moment of the rare-earth systems, i.e. $4.63 \alpha$. It should be pointed out that the actual process is of quantum nature and is much more complicated than what we assumed. However, the above phenomenological approach provides a simple explanation for the effect of the dynamic IVCT process. 


\section{[S5] Magnetic properties}

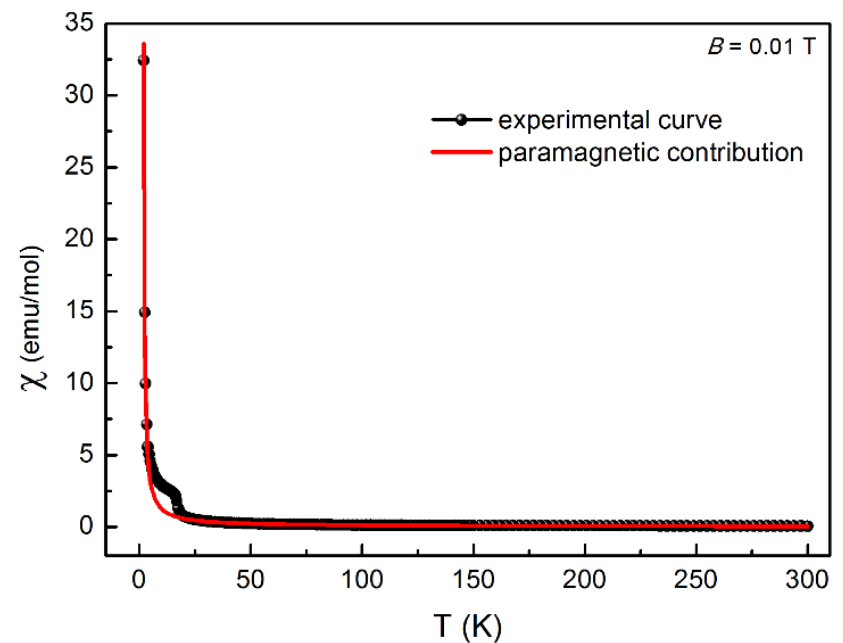

Figure S12. The magnetic susceptibilities of Eug $\mathrm{MgS}_{2} \mathrm{~B}_{20} \mathrm{O}_{41}$ measured at $\boldsymbol{B}=0.01 \mathrm{~T}$ in the cooling cycle (black curve). The paramagnetic contribution due to the presence of a trace amount of lattice defects or other impurities is fitted by Curie-Weiss law $\chi=\frac{10.59}{T-1.68}$ (red curve). ${ }^{4 b, 19}$

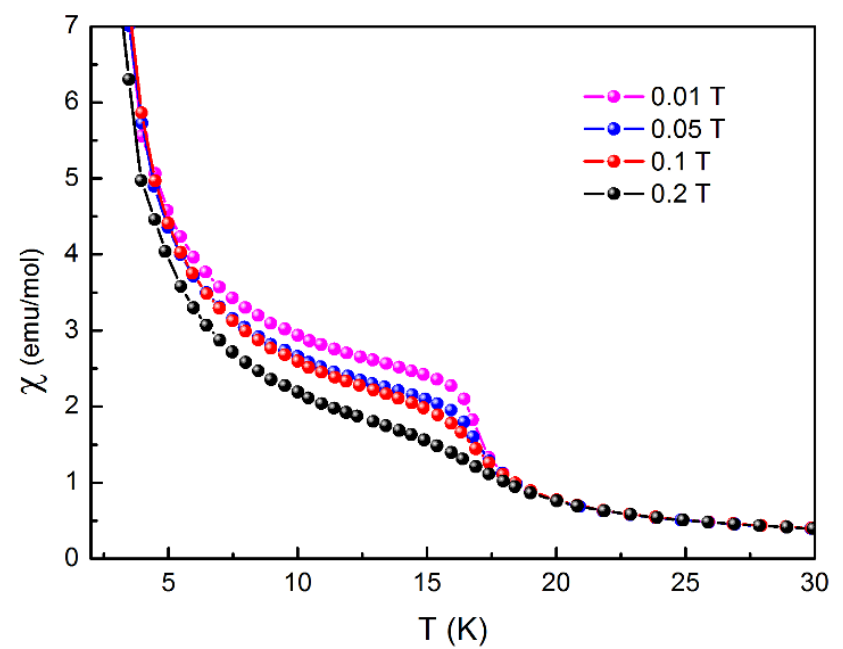

Figure S13. The magnetic susceptibilities of $\mathrm{Eu}_{9} \mathrm{MgS}_{2} \mathrm{~B}_{20} \mathrm{O}_{41}$ measured at $\boldsymbol{B}=0.01,0.05,0.1$ and $0.2 \mathrm{~T}$ in the cooling cycle. 


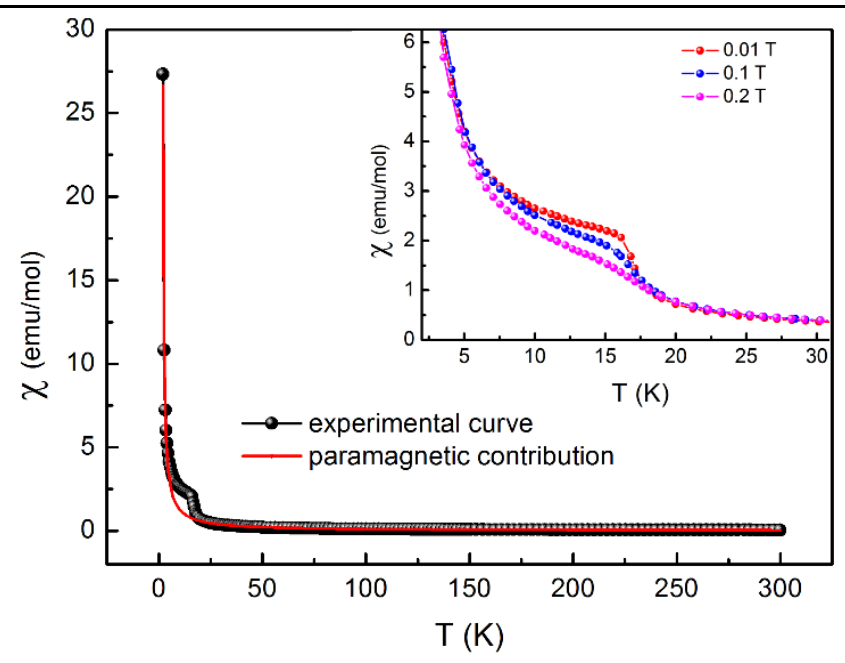

Figure S14. The field-cooled magnetic susceptibilities of $\mathrm{Eu}_{9} \mathrm{MgS}_{2} \mathrm{~B}_{20} \mathrm{O}_{41}$ measured at $\boldsymbol{B}=0.01$ $\mathrm{T}$ in the heating cycle (black curve). The paramagnetic contribution due to the presence of a trace amount of lattice defects or other impurities is fitted by Curie-Weiss law $\chi=\frac{10.86}{T-1.60}$ (red curve). ${ }^{4 b, 19}$ The inset shows the field-cooled magnetic susceptibilities measured at the magnetic field of $0.01,0.1$ and $0.2 \mathrm{~T}$.

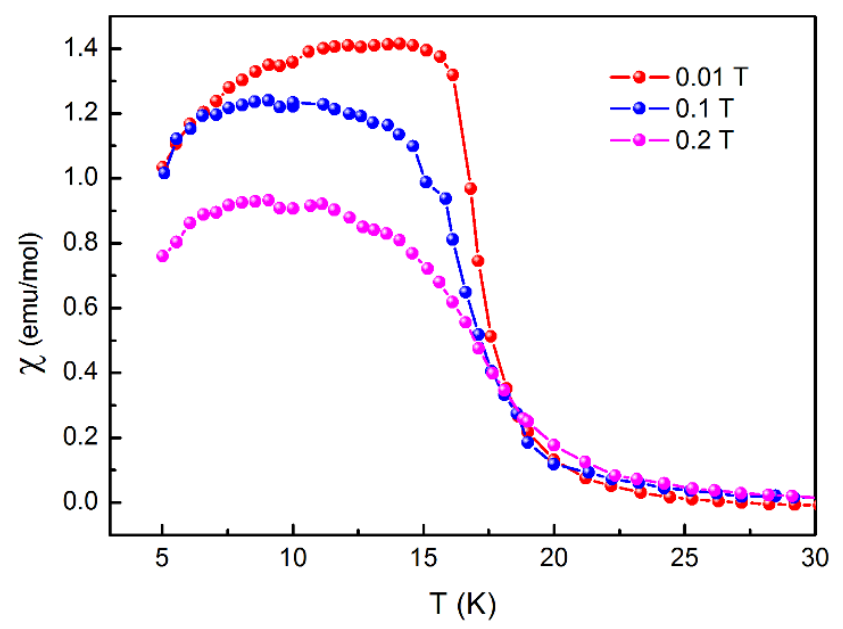

Figure S15. The field-cooled magnetic susceptibilities of $\mathrm{Eu}_{9} \mathrm{MgS}_{2} \mathrm{~B}_{20} \mathrm{O}_{41}$ measured at $\boldsymbol{B}=0.01$, 0.1 and $0.2 \mathrm{~T}$ in the heating cycle. 


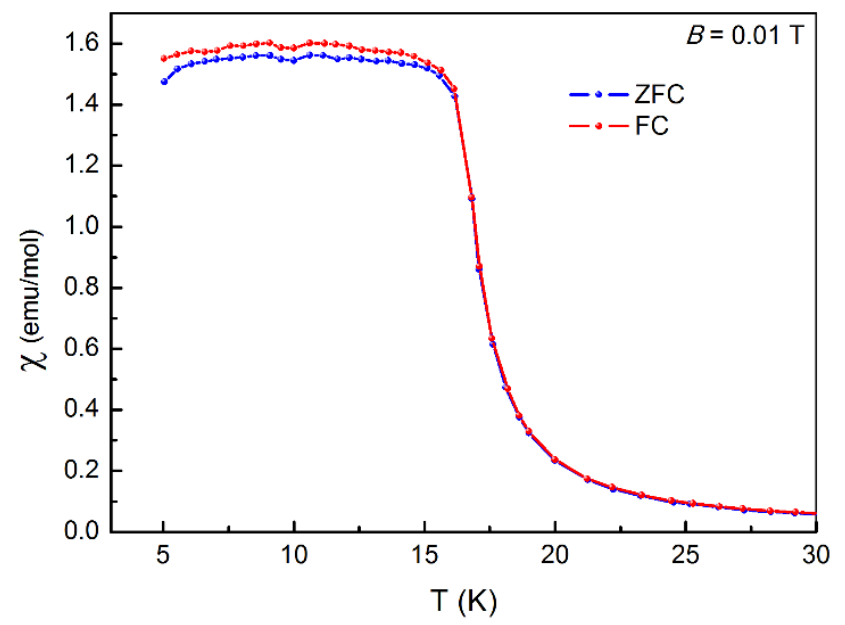

Figure S16. The field-cooled (red curve) and zero-field-cooled (blue curve) magnetic susceptibilities measured at $\boldsymbol{B}=0.01 \mathrm{~T}$ in the heating cycle.

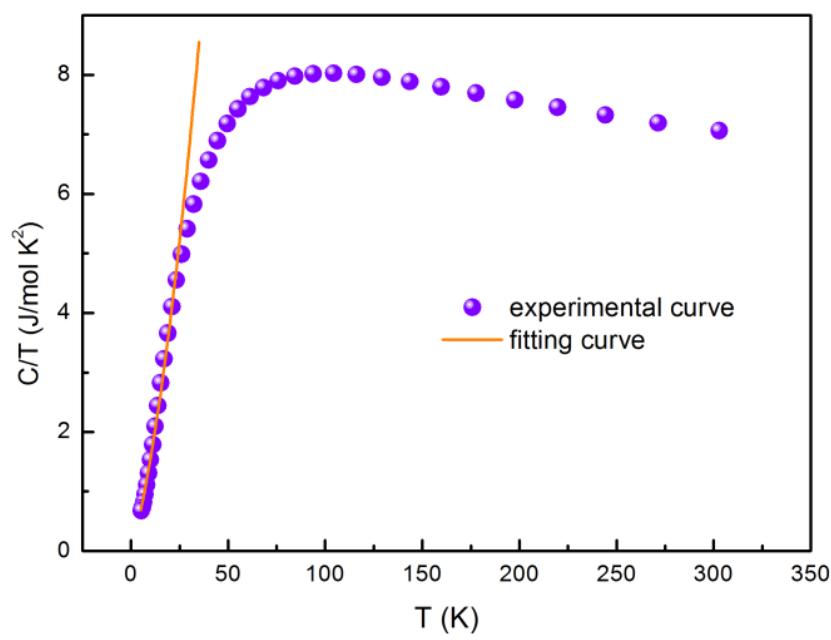

Figure S17. Temperature dependence of the specific heat $C$ of EMSBO represented as $C / T$ vs. $T$. The solid dots show the experimental data points. The data of the specific heat below $24 \mathrm{~K}$ are fitted with a power series, which results in a relation $\mathrm{C} / T=\mathrm{A} T+\mathrm{B} T^{2},{ }^{20}$ with $\mathrm{A}=0.11944$ and $\mathrm{B}=0.00357$. The fitting leads to a dominant behavior of the specific heat, $\mathrm{C} \sim \mathrm{A} T^{2}$, which is exactly the characteristic expected for a spin liquid system ${ }^{20}$. The negligible term $\mathrm{C} \sim \mathrm{B} T^{3}$ corresponds to the contribution of phonons. 
Table S5. The calculated J values (in K) of the important spin exchange interactions.

\begin{tabular}{|c|c|c|c|c|c|}
\hline & \multicolumn{2}{|c|}{$\mathrm{Eu}(1)$ layer } & \multicolumn{2}{|c|}{$\mathrm{Eu}(2)$ layer } & \multirow{3}{*}{$\frac{\text { Interlayer }}{\operatorname{Eu}(1)-\operatorname{Eu}(2)}$} \\
\hline & Eu(bridge O)- & $\mathrm{Eu}($ cap O)- & $\mathrm{Eu}(\mathrm{O})-\mathrm{Eu}(\mathrm{O})$ & $\mathrm{Eu}(\mathrm{S})-\mathrm{Eu}(\mathrm{S})$ & \\
\hline & Eu(bridge $\mathrm{O}$ ) & $\operatorname{Eu}(\operatorname{cap} O)$ & & & \\
\hline $\mathrm{J}(\mathrm{K})$ & -0.32 & -1.02 & -1.74 & -3.18 & -2.38 \\
\hline
\end{tabular}




\section{References:}

(1) (a) Guo, S.-P.; Chi, Y.; Xue, H.-G., $\mathrm{Sm}_{3} \mathrm{~S}_{3} \mathrm{BO}_{3}$ : the first sulfide borate without S-O and B-S bonds. Inorg. Chem. 2015, 54, 11052. (b) Chi, Y.; Guo, S.-P.; Kong, H.-J.; Xue, H.-G., Crystal and electronic structures, optical and magnetic properties of novel rare-earth sulfide borates $\mathrm{RE}_{3} \mathrm{~S}_{3} \mathrm{BO}_{3}(\mathrm{RE}=\mathrm{Sm}, \mathrm{Gd})$. New J. Chem. 2016, 40, 6720. (c) Guo, S.-P.; Chi, Y.; Xue, H.-G., $\mathrm{SnI}_{4} \cdot\left(\mathrm{S}_{8}\right)_{2}$, a novel adduct-type infrared second-order nonlinear optical crystal. Angew. Chem. Int. Ed. 2018, 57, 11540 .

(2) Dolomanov, O. V.; Bourhis, L. J.; Gildea, R. J.; Howard, J. A. K.; Puschmann, H., OLEX2: A complete structure solution, refinement and analysis program. J. Appl. Crystallogr. 2009, 42, 339.

(3) Sheldrick, G. M., Crystal structure refinement with SHELXL. Acta Crystallogr. C 2015, 71, 3.

(4) (a) Timofeeva, N. I.; Salibekov, S. E.; Romanovich, I. V., Synthesis and properties of rare earth titanates. Inorg. Mater. 1971, 7, 785. (b) Sanders, M. B.; Baroudi, K. M.; Krizan, J. W.; Mukadam, O. A.; Cava, R. J., Synthesis, crystal structure, and magnetic properties of novel 2D kagome materials $\mathrm{RE}_{3} \mathrm{Sb}_{3} \mathrm{Mg}_{2} \mathrm{O}_{14}(\mathrm{RE}=\mathrm{La}, \mathrm{Pr}, \mathrm{Sm}, \mathrm{Eu}, \mathrm{Tb}, \mathrm{Ho})$ : Comparison to $\mathrm{RE}_{3} \mathrm{Sb}_{3} \mathrm{Zn}_{2} \mathrm{O}_{14}$ family. Phys. Status Solidi B 2016, 253, 2056. (c) Sanders, M. B.; Krizan, J. W.; Cava, R. J., $\mathrm{RE}_{3} \mathrm{Sb}_{3} \mathrm{Zn}_{2} \mathrm{O}_{14}(\mathrm{RE}=\mathrm{La}, \mathrm{Pr}, \mathrm{Nd}, \mathrm{Sm}, \mathrm{Eu}, \mathrm{Gd})$ : a new family of pyrochlore derivatives with rare earth ions on a 2D Kagomé lattice. J. Mater. Chem. C 2016, 4, 541.

(5) Bordet, P.; Gelard, I.; Marty, K.; Ibanez, A.; Robert, J.; Simonet, V.; Canals, B.; Ballou, R.; Lejay, P., Magnetic frustration on a Kagomé lattice in $\mathrm{R}_{3} \mathrm{Ga}_{5} \mathrm{SiO}_{14}$ langasites with $\mathrm{R}=\mathrm{Nd}$, $\mathrm{Pr}$. $J$. Phys.: Condens. Mat. 2006, 18, 5147.

(6) (a) Dun, Z. L.; Trinh, J.; Li, K.; Lee, M.; Chen, K. W.; Baumbach, R.; Hu, Y. F.; Wang, Y. X.; Choi, E. S.; Shastry, B. S.; Ramirez, A. P.; Zhou, H. D., Magnetic ground states of the rareearth tripod kagome lattice $\mathrm{Mg}_{2} \mathrm{RE}_{3} \mathrm{Sb}_{3} \mathrm{O}_{14}(\mathrm{RE}=\mathrm{Gd}$, Dy, Er). Phys. Rev. Lett. 2016, 116, 157201. (b) Dun, Z. L.; Trinh, J.; Lee, M.; Choi, E. S.; Li, K.; Hu, Y. F.; Wang, Y. X.; Blanc, N.; Ramirez, A. P.; Zhou, H. D., Structural and magnetic properties of two branches of the tripod-kagomelattice family $\mathrm{A}_{2} \mathrm{R}_{3} \mathrm{Sb}_{3} \mathrm{O}_{14}(\mathrm{~A}=\mathrm{Mg}, \mathrm{Zn} ; \mathrm{R}=\mathrm{Pr}, \mathrm{Nd}, \mathrm{Gd}, \mathrm{Tb}, \mathrm{Dy}, \mathrm{Ho}, \mathrm{Er}, \mathrm{Yb})$. Phys. Rev. B 2017, 95, 104439. (c) Zhou, H. D.; Vogt, B. W.; Janik, J. A.; Jo, Y. J.; Balicas, L.; Qiu, Y.; Copley, J. 
R.; Gardner, J. S.; Wiebe, C. R., Partial field-induced magnetic order in the spin-liquid kagome $\mathrm{Nd}_{3} \mathrm{Ga}_{5} \mathrm{SiO}_{14}$. Phys. Rev. Lett. 2007, 99, 236401.

(7) Ding, Z.-F.; Yang, Y.-X.; Zhang, J.; Tan, C.; Zhu, Z.-H.; Chen, G.; Shu, L., Possible gapless spin liquid in the rare-earth kagomé lattice magnet $\mathrm{Tm}_{3} \mathrm{Sb}_{3} \mathrm{Zn}_{2} \mathrm{O}_{14}$. Phys. Rev. B 2018, 98, 174404 .

(8) Zhu, Z.; Maksimov, P. A.; White, S. R.; Chernyshev, A. L., Disorder-induced mimicry of a spin liquid in $\mathrm{YbMgGaO}_{4}$. Phys. Rev. Lett. 2017, 119, 157201.

(9) (a) Au, Y. S.; Fu, W. T.; Ijdo, D. J. W., Crystal structure of $\mathrm{Ca}_{2} \mathrm{Ln}_{3} \mathrm{Sb}_{3} \mathrm{O}_{14}(\mathrm{Ln}=\mathrm{La}, \mathrm{Pr}, \mathrm{Nd}$ and Y): A novel variant of weberite. J. Solid State Chem. 2007, 180, 3166. (b) Fu, W. T.; IJdo, D. J. W., New rhombohedral pyrochlores $\mathrm{Ca}_{2} \mathrm{Ln}_{3} \mathrm{Sb}_{3} \mathrm{O}_{14}(\mathrm{Ln}=$ lanthanide and Y): Space group revised. J. Solid State Chem. 2015, 229, 330. (c) Piccinelli, F.; Carrasco, I.; Ma, C. G.; Srivastava, A. M.; Bettinelli, M., Disorder-induced breaking of the local inversion symmetry in rhombohedral pyrochlores $\mathrm{M}_{2} \mathrm{La}_{3} \mathrm{Sb}_{3} \mathrm{O}_{14}(\mathrm{M}=\mathrm{Mg}$ or $\mathrm{Ca})$ : A structural and spectroscopic investigation. Inorg. Chem. 2018, 57, 9241.

(10) Paddison, J. A.; Ong, H. S.; Hamp, J. O.; Mukherjee, P.; Bai, X.; Tucker, M. G.; Butch, N. P.; Castelnovo, C.; Mourigal, M.; Dutton, S. E., Emergent order in the kagome Ising magnet $\mathrm{Dy}_{3} \mathrm{Mg}_{2} \mathrm{Sb}_{3} \mathrm{O}_{14}$. Nat. Commun. 2016, 7, 13842.

(11) (a) Mill, B. V.; Butashin, A. V.; Khodzhabagyan, G. G.; Belokoneva, E. L.; Belov, N. V., Modified rare-earth gallates with the structure of $\mathrm{Ca}_{3} \mathrm{Ga}_{2} \mathrm{Ge}_{4} \mathrm{O}_{14}$. Dokl. Akad. Nauk SSSR 1982, 264, 1385. (b) Kaminskii, A. A.; Mill, B. V.; Khodzhabagyan, G. G.; Konstantinova, A. F.; Okorochkov, A. I.; Silvestrova, I. M., Investigation of trigonal $\left(\mathrm{La}_{1-\mathrm{x}} \mathrm{Nd}_{\mathrm{x}}\right)_{3} \mathrm{Ga}_{5} \mathrm{SiO}_{14}$ Crystals. I. Growth and optical properties. Phys. Stat. Sol. (a) 1983, 80, 387.

(12) Zhou, H. D.; Wiebe, C. R.; Jo, Y. J.; Balicas, L.; Urbano, R. R.; Lumata, L. L.; Brooks, J. S.; Kuhns, P. L.; Reyes, A. P.; Qiu, Y.; Copley, J. R.; Gardner, J. S., Chemical pressure induced spin freezing phase transition in kagome Pr langasites. Phys. Rev. Lett. 2009, 102, 067203.

(13) (a) Kresse, G.; Furthmüller, J., Efficiency of ab-initio total energy calculations for metals and semiconductors using a plane-wave basis set. Comp. Mater. Sci. 1996, 6, 15. (b) Kresse, G.; Furthmüller, J., Efficient iterative schemes for ab initio total-energy calculations using a planewave basis set. Phys. Rev. B 1996, 54, 11169. 
(14) (a) Hohenberg, P.; Kohn, W., Inhomogeneous electron gas. Phys. Rev. 1964, 136, B864. (b)

Kohn, W.; Sham, L. J., Self-consistent equations including exchange and correlation effects. Phys. Rev. 1965, 140, A1133.

(15) Perdew, J. P.; Burke, K.; Ernzerhof, M. J., Generalized gradient approximation made simple. Phys. Rev. Lett. 1996, 77, 3865.

(16) Kresse, G.; Marsman, M.; Furthmüller, J., Vasp the guide. Vienna, 2016.

(17) Wan, X.; Dong, J.; Savrasov, S. Y., Mechanism of magnetic exchange interactions in europium monochalcogenides. Phys. Rev. B 2011, 83, 205201.

(18) Hush, N. S., Intervalence-transfer absorption. Part 2. Theoretical considerations and spectroscopic data. Prog. Inorg. Chem. 1967, 391.

(19) Tang, Y.; Peng, C.; Guo, W.; Wang, J. F.; Su, G.; He, Z., Octa-kagomé lattice compounds showing quantum critical behaviors: spin gap ground state versus antiferromagnetic ordering. J. Am. Chem. Soc. 2017, 139, 14057.

(20) (a) Helton, J. S.; Matan, K.; Shores, M. P.; Nytko, E. A.; Bartlett, B. M.; Yoshida, Y.; Takano, Y.; Suslov, A.; Qiu, Y.; Chung, J.-H.; Nocera, D. G.; Lee, Y. S., Spin dynamics of the spin-1/2 kagomé lattice antiferromagnet $\mathrm{ZnCu}_{3}(\mathrm{OH})_{6} \mathrm{Cl}_{2}$. Phys. Rev. Lett. 2007, 98, 107204. (b) Nakatsuji, S.; Nambu, Y.; Tonomura, H.; Sakai, O.; Jonas, S.; Broholm, C.; Tsunetsugu, H.; Qiu, Y.; Maeno, Y., Spin disorder on a triangular lattice. Science 2005, 309, 1697. (c) Sindzingre, P.; Misguich, G.; Lhuillier, C.; Bernu, B.; Pierre, L.; Waldtmann, C.; Everts, H.-U., Magnetothermodynamics of the spin-1/2 kagomé antiferromagnet. Phys. Rev. Lett. 2000, 84, 2953. 